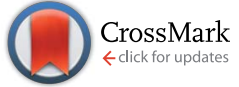

Cite this: RSC Adv., 2015, 5, 93187

Received 16th July 2015

Accepted 13th October 2015

DOI: $10.1039 / \mathrm{c} 5 \mathrm{ra} 13996 \mathrm{a}$

www.rsc.org/advances

\section{Synthesis and characterization of poly-aluminum silicate sulphate (PASS) for ultra-low density fiberboard (ULDF)}

\author{
Tingjie Chen, ${ }^{a}$ Min Niu, ${ }^{a}$ Xiaodong Wang, ${ }^{b}$ Wei Wei, ${ }^{a}$ Jinghong Liu ${ }^{\star a}$ \\ and Yongqun $\mathrm{Xie}^{\star \mathrm{a}}$
}

Poly-aluminum silicate sulphate (PASS) was synthesized in a mixed aqueous solution of sodium silicate and aluminum silicate via a sol-gel method for use in ultra-low density fiberboard (ULDF). The preparation conditions were optimized by using response surface methodology. The effects and interactions of the Si/Al molar ratio $\left(X_{1}\right), \mathrm{pH}$ value $\left(X_{2}\right)$ and temperature $\left(X_{3}\right)$ on the internal bond strength of ULDF were investigated. Research showed that the optimum internal bond strength (10.23 $\pm 0.64 \mathrm{kPa}$ ) was obtained under a Si/Al molar ratio of $2: 1, \mathrm{pH}$ value of 8 , and a temperature of $50{ }^{\circ} \mathrm{C}$. Analyses of the Fourier transform infra-red spectroscopy spectra confirmed that $\mathrm{Al}-\mathrm{O}-\mathrm{Si}$ bonds were formed between polysilicate and Al or its hydrolysate. The particle size analysis showed that the average size of PASS was $7.52 \mu \mathrm{m}$. Some of the PASS entered the cell wall and made a contribution to the improvement of the mechanical properties of ULDF.

\section{Introduction}

Ultra-low density fiberboards (ULDFs) are manufactured using a liquid frothing method. ${ }^{1}$ These materials have many excellent properties including low thermal conductivities, and good sound absorption, etc. ${ }^{1-5}$ They are a promising alternative to petroleum based products because they are made from plant fibers and could be used for building insulation materials and packaging buffer materials. However, their applications are restricted due to their poor mechanical properties which correspond to their ultra-low density (ranging from 10 to $90 \mathrm{~kg}$ $\mathrm{m}^{-3}$ ) and porosity. ${ }^{4,5}$ Recently, interest has increased in modifying the mechanical properties of wood-based materials through a variety of methods such as using inorganic compounds..$^{5-10}$

Silicon materials such as water glass and aluminum compounds can improve the heat resistance of wood-based materials. When aluminum salts are heated, they absorb a lot of heat from the dehydration reaction. ${ }^{11}$ In addition, silicon materials can also ameliorate the mechanical properties of wood composites. ${ }^{7,8,12}$ Poly-aluminum silicate sulphate (PASS) is one of the inorganic polymer coagulants which can be prepared through polymerization of poly-silicic acid and hydroxylated aluminium salts. ${ }^{13}$ The polysilicic acid can neutralize the

${ }^{a}$ College of Material Engineering, Fujian Agriculture and Forestry University, 350002, Fuzhou, Fujian, China. E-mail: fjxieyq@hotmail.com; 314515363@qq.com; Fax: +86 591 83789135; Tel: +86 59183789307

${ }^{b}$ Division of Wood Technology and Engineering, Luleå University of Technology, 93187, Forskargatan 1, Skellefteå, Sweden positive charge in polyaluminum and also combine with $\mathrm{Al}$ and its hydrolysis products through $\mathrm{Al}-\mathrm{O}-\mathrm{Si}$ bonds to form hydroxylaluminosilicate due to its negatively charged polymer. ${ }^{14,15}$ PASS has many distinct abilities including charge neutralization, adsorption bridging and sweep coagulation. When it is stirred with fibers, it covers the surface of the fibers or even interacts with plant fibers which improves the properties of the fibers or fiber composites..$^{16,17}$

It's worth noting that the properties of inorganic polymer coagulants are affected by many factors such as aging temperature, silicon dose, $\mathrm{pH}$ value, and $\mathrm{Si} / \mathrm{Al}$ ratio. For example, the coagulation efficiency of an aluminum-silicate polymer composite (PASiC) increases with rising basicity, however, the PASiC products tend to become cloudy or partly gelatinous in this case.$^{18} \mathrm{Li}$ et al. showed that the coagulation performance of a poly-silicic-cation coagulant was affected by the $\mathrm{pH}$ value. The $\mathrm{Si} / \mathrm{Al}$ ratio also played a crucial role in the properties of inorganic polymer coagulants. Different positive charges and molecular weights of PASiC coagulants were obtained when they were prepared in different $\mathrm{Si} / \mathrm{Al}$ ratios. For example, an increase in the $\mathrm{Si} / \mathrm{Al}$ ratio would increase the amount of polymeric coordination. ${ }^{18-21}$

Although the coagulation performances of various inorganic polymer coagulants in water and waste water treatment have been already studied by many researchers, there is still no research on the effects of PASS with different characteristics on the mechanical properties of ULDF. To systemically study the influence of PASS on the mechanical properties of ULDF, PASS materials with different Si/Al molar ratios, $\mathrm{pH}$ values, and temperatures were prepared and added into the preparation of 
ULDF. Additionally, to obtain the optimal preparation conditions of PASS, a standard response surface methodology (RSM) called central composite design (CCD) was used. The chemical structures and particle sizes of the PASS materials were examined and analyzed.

\section{Experimental}

\subsection{Materials}

Kraft pulp (KP, spruce-pine-fir; Tembec Inc., Canada) was utilized as a raw material to manufacture ULDF. Aluminum sulfate and sodium silicate, purchased from Tianjin Fuchen Chemical Reagents Factory (China), were used to generate the poly-aluminum silicate sulphate (PASS). Sodium dodecylbenzene sulfonate, a foaming agent, was purchased from Jiangsu Qingting Washing Products Co., Ltd. (China). Sulfuric acid was purchased from Tianjin Fuchen Chemical Reagents Factory (China) to acidize the sodium silicate.

\subsection{Methods}

2.2.1 Preparation of poly-aluminum silicate sulphate. A PASS solution was formed through a mutual reaction between sodium silicate and aluminum sulfate in a sol-gel process. The aluminum sulfate solution was added to a $500 \mathrm{~mL}$ tri-necked round-bottom flask with a magnetic stir bar, experiencing a vigorous stirring for $10 \mathrm{~min}$ at a set temperature. The sodium silicate solution was acidized using a dilute sulfuric acid to obtain the desired $\mathrm{pH}$ value. Then the quantitative polysilicic acid solution was added into the flask slowly to obtain the PASS. A schematic representation of the manufacture of PASS is shown in Fig. 1.

2.2.2 Preparation of ultra-low density fibreboard. Ultra-low density fiberboards of $200 \mathrm{~mm} \times 200 \mathrm{~mm} \times 50 \mathrm{~mm}(L \times W \times H)$ were manufactured separately using various parameters in a demonstration line as described by Chen et al., ${ }^{22}$ with a target bulk density of $50-90 \mathrm{~kg} \mathrm{~m}^{-3}$. The preparation process of the fiberboards is described in Fig. 2. The amount of dry pulp fiber was $55 \mathrm{~g}$. The $500 \mathrm{~mL}$ PASS solution, which was approximately $22.7 \%$ of the dry pulp fiber, was added into this paper. Additionally, the additives polyacrylamide resin, alkyl ketene dimer water repellent (AKD), chlorinated paraffin fire retardant, and

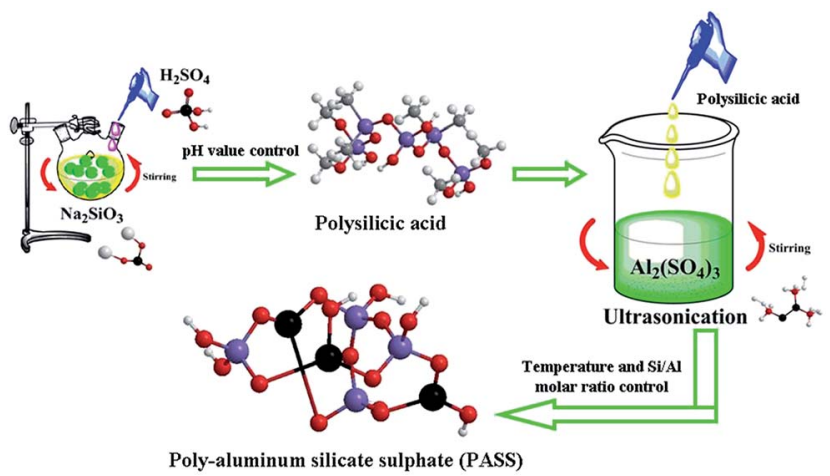

Fig. 1 Schematic representation of the manufacture of PASS.

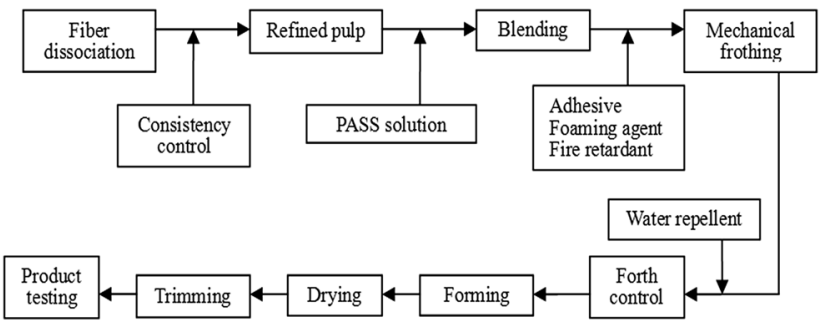

Fig. 2 The preparation process of ULDFs.

sodium dodecylbenzene sulfonate surfactant (10\% concentration, foaming agent) were added during different manufacturing stages for all of the specimens, at $20 \mathrm{~mL}, 50 \mathrm{~mL}$, $46 \mathrm{~g}$ and $80 \mathrm{~mL}$, respectively.

\subsection{Experimental design}

The Si/Al molar ratio $\left(X_{1}\right), \mathrm{pH}$ value $\left(X_{2}\right.$, the $\mathrm{pH}$ value of sodium silicate solutions) and temperature $\left(X_{3}\right.$, the aging temperature of PASS) were chosen as the variables. The internal bond strength $(Y)$ was regarded as their function. A standard RSM design CCD was applied to study the effects of $X_{1}, X_{2}$ and $X_{3}$ on $Y$. The software Design-Expert (Trial Version 8.0.6) was used to analyze the data and build the models. The selection range of each variable which was determined by the previous single factor experiment is shown in Table 1. The CCD consisted of 20 experiments including eight factorial experiments, six star points and another six replicated at the central point of the designed model to estimate the pure error sum of squares. The detailed parameter variables of PASS are given in Table 1.

\subsection{Internal bond strength of ultra-low density fibreboard}

The internal bond strength (IB) of each ULDF was tested in accordance with GB/T $17657 .{ }^{23}$ The size of the specimens for the testing of the internal bond strength was $50 \mathrm{~mm} \times 50 \mathrm{~mm} \times$ $40 \mathrm{~mm}(L \times W \times H)$. All of the results were the average of five replications for each ULDF group.

\subsection{Functional groups and particle sizes of PASS}

The functional groups in the PASS were characterized using Fourier transform infrared (FTIR) spectroscopy. The FTIR analysis of PASS was performed by means of a Nicolet 380 FTIR spectrometer (Thermo Electron Instruments, USA), employing the $\mathrm{KBr}$ pellet method, and taking 32 scans for each sample with a resolution of $4 \mathrm{~cm}^{-1}$, ranging from 4000 to $400 \mathrm{~cm}^{-1}$. The

Table 1 Levels of parameter variables used in the RSM design for ULDFs

\begin{tabular}{llllll}
\hline & Levels & & & & \\
\hline Coded-variables $\left(X_{\mathrm{i}}\right)$ & -1.682 & -1 & 0 & 1 & 1.682 \\
Si/Al molar ratio $\left(X_{1}\right)$ & $0.32: 1$ & $1: 1$ & $2: 1$ & $3: 1$ & $3.68: 1$ \\
pH values $\left(X_{2}\right)$ & 4.64 & 6.0 & 8.0 & 10.0 & 11.36 \\
Temperature $\left(X_{3},{ }^{\circ} \mathrm{C}\right)$ & 16.36 & 30 & 50 & 70 & 83.64
\end{tabular}


particle sizes of the PASS were determined using a laser particle size analyzer (BT-9300H, Bettersize Instruments Ltd., China). Each sample, with a concentration of $0.5 \%$, was tested over nearly 3 minutes with measurements ranging from 0.1 to $340.0 \mu \mathrm{m}$.

\section{Results and discussion}

\subsection{Model fitting}

The design matrix and the results of the RSM experiments for determining the effects of the three independent variables are shown in Table 2. The mathematical model representing the IB of ULDF against the function of the independent variables within the range under investigation is expressed as follows:

$$
\begin{aligned}
Y= & 10.23+0.63 X_{1}+0.41 X_{2}+0.33 X_{3}-0.055 X_{1} X_{2}+0.078 X_{1} X_{3} \\
& -0.077 X_{2} X_{3}-2.31 X_{1}{ }^{2}-1.48 X_{2}{ }^{2}-0.81 X_{3}{ }^{2}
\end{aligned}
$$

where $Y$ is the IB of the ULDF, whereas $X_{1}, X_{2}$ and $X_{3}$ are the coded variables for the $\mathrm{Si}-\mathrm{Al}$ molar ratio, $\mathrm{pH}$ value, and temperature, respectively.

In general, the exploration and optimization of a fitted response surface may produce poor or misleading results unless the model exhibits a good fit. ${ }^{24-27}$ As shown in Table 3, the model's fit was good because its $p$-value was less than 0.0001 and the lack of fit value was 0.0956 . The determination coefficient $\left(R^{2}\right)$ of this model was 0.9667 , which implied that $96.67 \%$ of the variations could be explained by the fitted model. The value of $R^{2}$ was in reasonable agreement with $R_{\text {adj }}^{2}$ which indicated a high degree of correlation between the observed and predicted value. ${ }^{28}$ So, the values of $R^{2}(0.9667)$ and $R_{\text {adj }}{ }^{2}(0.9368)$ in this model proved that the regression model could explain the true behavior of the system well.
The corresponding variables would be more significant with greater $F$-values and smaller $p$-values. ${ }^{29}$ As can be seen in Table 3 , the $F$-value (32.29) and $p$-value (less than 0.0001 ) implied that this model was significant and only a $0.01 \%$ chance that it could occur due to noise. On the contrary, the $F$-value (3.54) and $p$-value (0.0956) of the lack of fit implied that it was not significant and a $9.56 \%$ chance that it could occur due to noise. The $p$-values in this model indicated that $X_{1}, X_{2}$, and the three quadratic terms $\left(X_{1}{ }^{2}, X_{2}{ }^{2}\right.$, and $\left.X_{3}{ }^{2}\right)$ affected the IB of the ULDFs significantly, whereas $X_{3}, X_{1} X_{2}, X_{2} X_{3}$, and $X_{1} X_{3}$ were all insignificant to the response. The results also showed that the independent variable $X_{1}$ was the most significant factor on the experimental effect of the IB of ULDF.

\subsection{Analysis of response surface and optimization}

The effects of the variables on the IB of ULDF are shown in Fig. 3. Here, the relationship between the parameters and response variable are illustrated in a $3 \mathrm{D}$ representation of the response surface and the corresponding contour plot.

The results showed that the variables $X_{1}$ and $X_{2}$ played an important role in the IB of ULDFs, whereas $X_{3}$ did not. At a Si/Al molar ratio of $1.8: 1-2.2: 1$ and a $\mathrm{pH}$ value of 7.8-8.1, a maximal IB (10.23 kPa) could be determined (Fig. 3a). But, at a given $\mathrm{Si} / \mathrm{Al}$ molar ratio, the IB of ULDFs decreased with too low or too high $\mathrm{pH}$ values. This was because the morphostructure of the fibers and the foaming system of the ULDF might be affected by the low or high $\mathrm{pH}$ value. Additionally, the particle size of PASS was small at low $\mathrm{pH}$ values which might limit them leaving in ULDFs, whereas the particle size was large at high $\mathrm{pH}$ values which would not be helpful to the distribution of $\mathrm{Si} / \mathrm{Al}$ compounds on the fiber surfaces. On the other hand, the decrease in IB at higher $\mathrm{Si} / \mathrm{Al}$ molar ratios was possibly due to

\begin{tabular}{|c|c|c|c|c|c|}
\hline \multirow[b]{2}{*}{ Run no. } & \multicolumn{3}{|l|}{ Coded levels } & \multicolumn{2}{|c|}{ Internal bond strength (kPa) } \\
\hline & $\mathrm{Si}-\mathrm{Al}$ molar ratio $\left(X_{1}\right)$ & $\mathrm{pH}$ value $\left(X_{2}\right)$ & Temperature $\left(X_{3},{ }^{\circ} \mathrm{C}\right)$ & Experimental & Predicted \\
\hline 1 & $-1(1: 1)$ & $-1(6.0)$ & $-1(30)$ & 3.61 & 4.20 \\
\hline 2 & $1(3: 1)$ & -1 & -1 & 5.15 & 5.43 \\
\hline 3 & -1 & $1(10.0)$ & -1 & 4.83 & 5.28 \\
\hline 4 & 1 & 1 & -1 & 5.94 & 6.29 \\
\hline 5 & -1 & -1 & $1(70)$ & 4.48 & 4.87 \\
\hline 6 & 1 & -1 & 1 & 6.12 & 6.41 \\
\hline 7 & -1 & 1 & 1 & 5.18 & 5.64 \\
\hline 8 & 1 & 1 & 1 & 6.81 & 6.96 \\
\hline 9 & $-1.68(0.32: 1)$ & $0(8.0)$ & $0(50)$ & 3.40 & 2.63 \\
\hline 10 & $1.68(3.68: 1)$ & 0 & 0 & 5.03 & 4.76 \\
\hline 11 & $0(2: 1)$ & $-1.68(4.64)$ & 0 & 5.94 & 5.38 \\
\hline 12 & 0 & $1.68(11.36)$ & 0 & 7.22 & 6.74 \\
\hline 13 & 0 & 0 & $-1.68(16.36)$ & 8.01 & 7.38 \\
\hline 14 & 0 & 0 & $1.68(83.64)$ & 8.91 & 8.50 \\
\hline 15 & 0 & 0 & 0 & 10.10 & 10.23 \\
\hline 16 & 0 & 0 & 0 & 10.31 & 10.23 \\
\hline 17 & 0 & 0 & 0 & 9.97 & 10.23 \\
\hline 18 & 0 & 0 & 0 & 10.77 & 10.23 \\
\hline 19 & 0 & 0 & 0 & 10.48 & 10.23 \\
\hline 20 & 0 & 0 & 0 & 9.59 & 10.23 \\
\hline
\end{tabular}

Table 2 Central composite design and the response to the internal bond strength 
Table 3 Analysis of variance for the regression model for the internal bond strength ${ }^{a}$

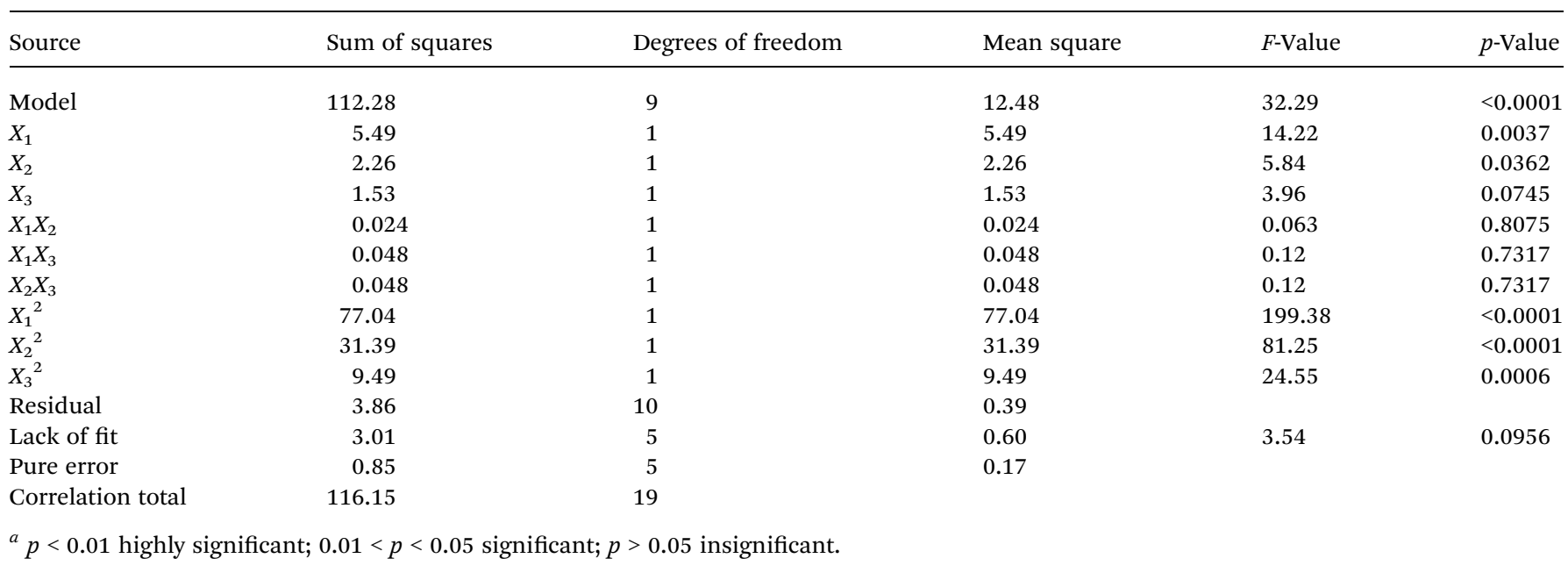
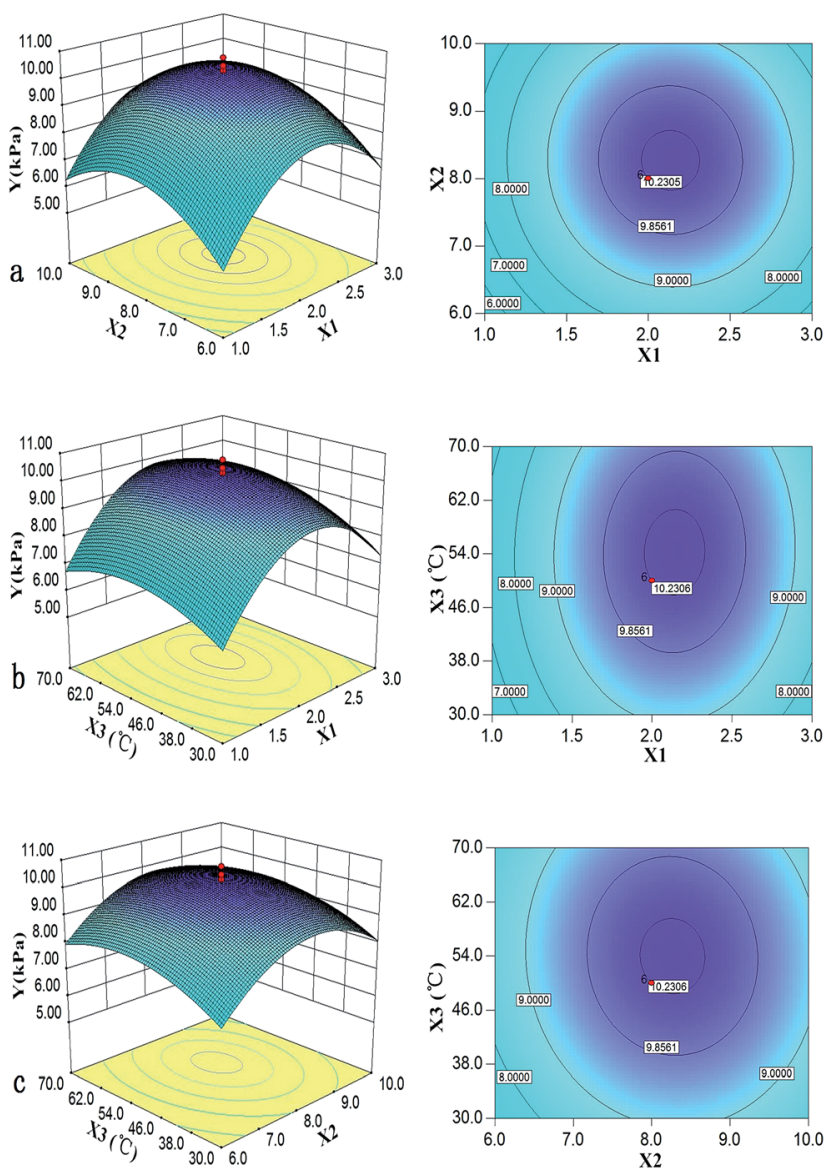

Fig. 3 Response surface plots for the maximum IB of ULDFs. (a) Effects of the Si/Al molar ratio and $\mathrm{pH}$ value on the IB of ULDFs; (b) effects of the Si/Al molar ratio and temperature on the IB of ULDFs; (c) effects of the $\mathrm{pH}$ value and temperature on the IB of ULDFs.

the distribution of additives and their charge neutralization which was the major and effective mechanism for the absorption of PASS on the fiber surface. ${ }^{22,30}$ The IB of ULDFs increased with temperature, especially within the range from 45 to $60{ }^{\circ} \mathrm{C}$, but declined slightly at higher temperatures (Fig. 3b). This was because the particle sizes of PASS were larger at higher temperatures which are always prone to agglomerate on the fiber surface. Fig. $3 \mathrm{c}$ shows the combined effect of $\mathrm{pH}$ value and temperature on the IB of ULDFs at a constant $\mathrm{Si} / \mathrm{Al}$ molar ratio $(2: 1)$. The result was elliptical, indicating significant interactive effects of the two independent variables on the IB of ULDFs. ${ }^{31}$

As seen in Fig. 3, the interaction between the $\mathrm{Si}-\mathrm{Al}$ molar ratio $\left(X_{1}\right)$ and the other two variables $\left(X_{2}, X_{3}\right)$ was significant. This was because more and more hydroxyl ions were added as the $\mathrm{pH}$ value increased which made the formation of sediment between aluminium and silicate ions easier. The hydrolyses of aluminium and silicate were significantly affected by the temperature of the solution. Meanwhile, there was almost no interaction between the $\mathrm{pH}$ value $\left(X_{2}\right)$ and temperature $\left(X_{3}\right)$. The $\mathrm{pH}$ value of the solution might be affected by the temperature but not significantly.

Based on eqn (1) which was derived from the computational program, the optimal PASS conditions for ULDFs were a Si/Al molar ratio of $2.14: 1, \mathrm{pH}$ value of 8.26 , and a temperature of $54.13{ }^{\circ} \mathrm{C}$. Taking the practical operating conditions into consideration, some conditions were modified as follows: a Si/Al molar ratio of $2: 1, \mathrm{pH}$ value of 8 , and a temperature of $50{ }^{\circ} \mathrm{C}$. Under these conditions, an average of $10.23 \pm 0.64 \mathrm{kPa}$ was obtained, which is close to the model predicted value of $10.34 \mathrm{kPa}$. Compared to the control specimen $(2.5 \mathrm{kPa})$, the IB of ULDF under the optimal conditions was increased by $313.6 \%$. These results confirmed that the model adequately reflected the expected optimization and eqn (1) was satisfactory and accurate.

\subsection{Functional groups in PASS}

Schematics of the synthesis of a Si sol and PASS are illustrated in Fig. 5. First, the $\mathrm{Si}$ sol was obtained under $\mathrm{H}_{2} \mathrm{SO}_{4}$ catalysis conditions. PASS was developed after the $\mathrm{Si}$ sol was added slowly to an $\mathrm{Al}_{2}\left(\mathrm{SO}_{4}\right)_{3}$ solution under ultrasound-assisted conditions. The FT-IR spectrum provided much information 


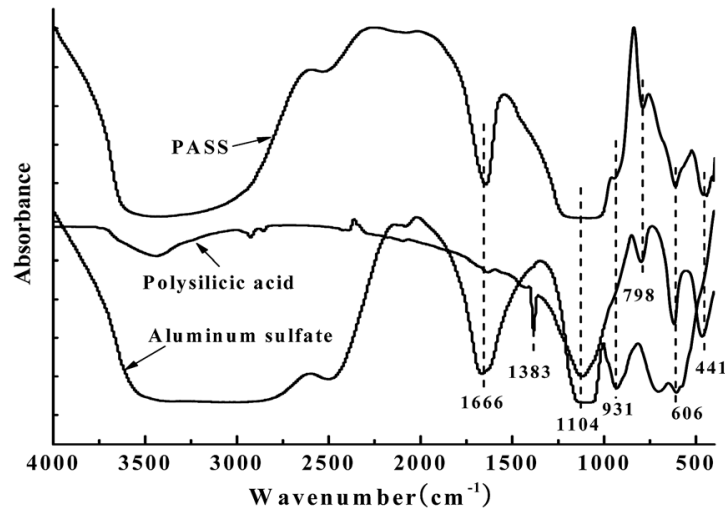

Fig. 4 FTIR profiles of polysilicic acid, aluminum sulfate and PASS

about the structure of the material, clearly revealing the combined mode of the $\mathrm{Si}$ and $\mathrm{Al}$ compounds. ${ }^{32}$ In order to explore the functional groups in the PASS, the infrared spectra of polysilicic acid, aluminum sulfate, and PASS are shown in Fig. 4.

The peaks at around 3400 and $1666 \mathrm{~cm}^{-1}$ were attributed to the $-\mathrm{OH}$ stretching vibrations and $-\mathrm{OH}$ bending vibrations, respectively. The peaks for aluminum sulfate at 1104, 931, and $606 \mathrm{~cm}^{-1}$ were attributed to the $\mathrm{SO}_{4}{ }^{2-}, \mathrm{Al}-\mathrm{O}-\mathrm{Al}$, and $\mathrm{Al}-\mathrm{OH}$ vibrations, respectively. The peaks for polysilicic acid at around 1380, 1114, 798, 619 and $441 \mathrm{~cm}^{-1}$ were ascribed to the contribution of the silicon-oxygen tetrahedral, $\mathrm{Si}-\mathrm{O}-\mathrm{Si}$ or $\mathrm{SO}_{4}{ }^{2-}$, $\mathrm{Si}-\mathrm{O}-\mathrm{Si}, \mathrm{SO}_{4}{ }^{2-}$, and $\mathrm{O}-\mathrm{Si}-\mathrm{O}$ vibrations, respectively. Comparing the infrared spectra of PASS to polysilicic acid and aluminum sulfate, the peak at $1100 \mathrm{~cm}^{-1}$ might be attributed to the $\mathrm{Si}-\mathrm{O}-$ $\mathrm{Si}, \mathrm{SO}_{4}{ }^{2-}$, or $\mathrm{Si}-\mathrm{O}-\mathrm{Al}$ vibration. This is due to the broad band in
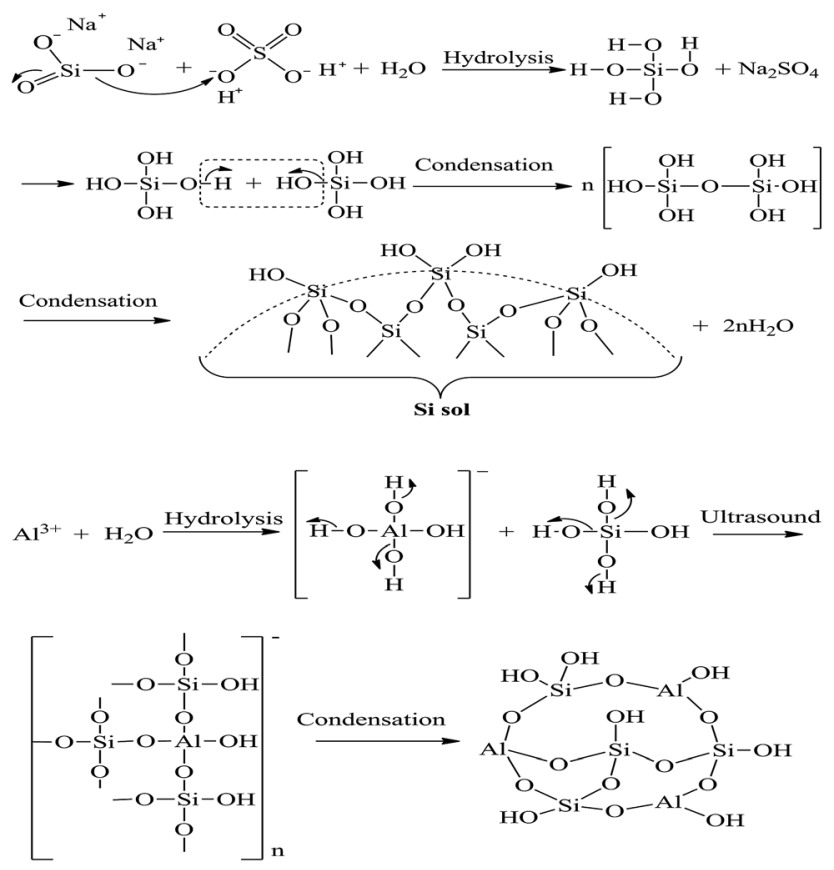

Fig. 5 Schematic synthesis of Si sol and PASS. the range of $1200-1000 \mathrm{~cm}^{-1}$ which usually corresponds to the mixed overlap of $\mathrm{Si}-\mathrm{O}-\mathrm{Si}$ and $\mathrm{Al}-\mathrm{O}-\mathrm{Si}$ bonds. ${ }^{33}$ In addition, the peak for PASS at $931 \mathrm{~cm}^{-1}$ was weakened. This is due to the polysilicic acid which could combine with $\mathrm{Al}$ and its hydrolysis product through Al-O-Si bonds to form hydroxylaluminosilicate, which led to the decrease in Al-O-Al bonds. Combining the results of Tang et al. and this study, the structure of the Si sol and PASS could be deduced as shown in Fig. $5 .^{32}$

\subsection{Particle size of PASS}

The particle size of PASS under the optimal preparation conditions is shown in Fig. 6.

As can be seen, the distribution of PASS' particle size in Fig. 6 , they was mainly distributed from $2 \mu \mathrm{m}$ to $15 \mu \mathrm{m}$. The average and largest particle sizes were $7.52 \mu \mathrm{m}$ and $18.98 \mu \mathrm{m}$, respectively. Combined with the cumulative curve, it could be found that there was $26.02 \%$ of PASS whose particle size was less than or equal to $5.25 \mu \mathrm{m}$. Due to the porosity of the fibers which have many pits ranging from $0.1 \mu \mathrm{m}$ to $5.0 \mu \mathrm{m}$ on their cell wall, some of the PASS with a smaller particle size could enter and leave the cell wall or cell cavity. ${ }^{22}$ Therefore, the PASS could not only deposit on the fiber surface through charge neutralization or adsorption bridging, but enter the cell cavity through the fiber pits and then become a sediment to enhance the mechanical properties of ULDF. ${ }^{4}$

On the contrary, the efficiency of coagulants in waste water treatment might be influenced by increasing the $\mathrm{Si} / \mathrm{Al}$ ratio and $\mathrm{pH}$ value. The results were different from the PASS for ULDFs. The study by Yang et al. showed that for a given $\mathrm{Si} / \mathrm{Al}$ ratio, an increase in $\mathrm{pH}$ value increased the DOC removal efficiency. ${ }^{21}$ This was because that higher $\mathrm{pH}$ value produced larger molecular sized products which would enhance aggregating efficiency. Additionally, for a given $\mathrm{pH}$ value, the DOC removal efficiency increased then decreased when the $\mathrm{Si} / \mathrm{Al}$ ratio increased. This was because of the interaction between hydrolyzed $\mathrm{Al}$ species and polysilicic acid which would decrease the positive charge and increased the molecular weight of the coagulant. ${ }^{11}$

In this study, for a given $\mathrm{Si} / \mathrm{Al}$ ratio and temperature, an increase in $\mathrm{pH}$ value would increase the particle size of PASS.

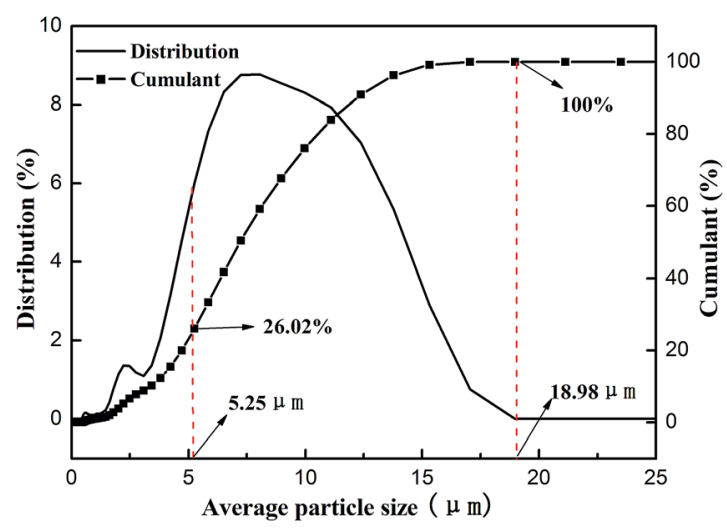

Fig. 6 Particle size of PASS under the optimal preparation conditions. 
Table 4 Particle size of PASS and the internal bond strength of ultra-low density fiberboards and similar coagulants for waste water treatment in the literature

\begin{tabular}{|c|c|c|c|c|c|c|}
\hline PASS & $\mathrm{Si}-\mathrm{Al}$ molar ratio & Temperature $\left({ }^{\circ} \mathrm{C}\right)$ & $\mathrm{pH}$ value & Particle size $(\mu \mathrm{m})$ & IB $(\mathrm{kPa})$ & $\begin{array}{l}\text { DOC removal } \\
\text { efficiency }\end{array}$ \\
\hline \multirow[t]{4}{*}{ This study } & \multirow[t]{4}{*}{2} & \multirow[t]{4}{*}{$30-40$} & 4 & 0.40 & 6.24 & - \\
\hline & & & 6 & 0.90 & 7.41 & - \\
\hline & & & 8 & 5.13 & 9.95 & - \\
\hline & & & 12 & 12.59 & 8.73 & - \\
\hline \multirow[t]{6}{*}{ Yang et al. ${ }^{21}$} & \multirow[t]{3}{*}{0.05} & \multirow[t]{3}{*}{ Ambient temperature } & 4 & - & - & $9.1 \%$ \\
\hline & & & 6 & - & - & $27.1 \%$ \\
\hline & & & 8 & - & - & $20.8 \%$ \\
\hline & 0.02 & \multirow[t]{3}{*}{ Ambient temperature } & \multirow[t]{3}{*}{4} & - & - & $7.7 \%$ \\
\hline & 0.05 & & & - & - & $9.1 \%$ \\
\hline & 0.10 & & & - & - & $3.4 \%$ \\
\hline
\end{tabular}

Different particle sizes of PASS were obtained at different $\mathrm{pH}$ values so the IB increased and later decreased in Table 4. The smaller particle size of PASS which was obtained under the conditions of lower $\mathrm{pH}$ values could enter into fibers; they might easy to run off when they were added in the preparation of ULDF. ${ }^{30}$ On the other hand, an increase in $\mathrm{pH}$ value would promote agglomeration and probably increased the molecular weight in PASS. The mechanical properties of ULDF would be affected by the large particle size of PASS which could influence the distribution of PASS on the fiber surface.

Taking these factors into consideration, the suitable particle size of PASS which played an important role in the mechanical properties of ULDF should be prepared. Combined with the results of FTIR and particle size, the optimal preparation conditions of PASS were valid for preparing ULDFs.

\section{Conclusions}

The mechanical properties of ULDFs could be effectively improved with PASS. The optimal conditions of PASS were predicted using response surface methodology, and a good internal bond strength of $10.23 \pm 0.64 \mathrm{kPa}$ was obtained. Taking the practical operating conditions into consideration, the optimal preparation conditions of PASS were: a Si/Al molar ratio of $2: 1$, $\mathrm{pH}$ value of 8 , and a temperature of $50{ }^{\circ} \mathrm{C}$. FTIR analysis confirmed that the added polysilicate reacted with $\mathrm{Al}$ and its hydrolysate. The particle size analysis indicated that the PASS could not only deposit on the fiber surface, but enters the cell cavity through the fiber pits to enhance the mechanical properties of ULDF.

\section{Acknowledgements}

This paper was supported by the Scientific Research Foundation of Graduate School of Fujian Agriculture and Forestry University (1122YB020) and the Studying Abroad Scholarships of China. The authors are also grateful for the financial support of the National Science and Technology Support Program (2008BADA9B01), the National Natural Science Foundation of China (NSFC) (30781982) and the Natural Science Foundation of Fujian Province (2015J01604).

\section{References}

1 Y. Q. Xie, Y. Chen and B. G. Zhang, China Wood Industry, 2004, 18(2), 30-32.

2 Y. Q. Xie, Q. J. Tong and Y. Chen, J. Korean Phys. Soc., 2008, 19(2), 106-110.

3 Y. Q. Xie, Y. Chen, Q. H. Wei and D. Z. Zhang, Journal of Fujian College of Forestry, 2008, 28(3), 203-207.

4 Y. Q. Xie, Q. J. Tong and Y. Chen, BioResources, 2011, 6(4), 4055-4066.

5 M. Niu, O. Hagman, X. D. Wang, Y. Q. Xie, O. Karlsson and L. L. Cai, BioResources, 2014, 9(2), 2415-2430.

6 Y. L. Fu, Y. Y. Mo, Y. X. Liu, M. J. Qiao and W. J. Chen, J. Zhejiang For. Coll., 2011, 28(4), 644-652.

7 S. Saka and T. Ueno, Wood Sci. Technol., 1997, 31(6), 457-466.

8 M. Shabir Mahr, T. Hübert, B. Schartel, H. Bahr, M. Sabel and H. Militz, J. Sol-Gel Sci. Technol., 2012, 64(2), 452-464.

9 Z. Lin, M. Niu and Y. Q. Xie, Journal of Fujian College of Forestry, 2013, 33(4), 371-376.

10 Y. Q. Xie and J. H. Liu, J. Beijing For. Univ., 2012, 34(1), 4-5.

11 B. Y. Gao, Q. Y. Yue and Y. Wang, Sep. Purif. Technol., 2007, 56(2), 225-230.

12 B. Unger, M. Bücker, S. Reinsch and T. Hübert, Wood Sci. Technol., 2012, 47(1), 83-104.

13 J. J. Lu, X. Z. Guo and H. Yang, Rare Met. Mater. Eng., 2008, 37(A02), 111-115.

14 Z. L. Yang, B. Y. Gao, Y. Wang, Q. Wang and Q. Y. Yue, J. Chem. Eng., 2011, 170(1), 107-113.

15 Z. L. Yang, B. Y. Gao, Y. Wang, Y. Q. Zhao and Q. Y. Yue, J. Environ. Sci., 2012, 24(11), 1908-1916.

16 Y. H. Jin, X. F. Du and K. Z. Zhang, Sci. Technol. Chem. Ind., 2011, 19(4), 11-13.

17 C. Y. Liu, S. L. Wang, J. Y. Shi and C. Y. Wang, Appl. Surf. Sci., 2011, 258(2), 761-765.

18 B. Y. Gao, B. Liu, T. Chen and Q. Y. Yue, J. Hazard. Mater., 2011, 187(1-3), 413-420.

19 R. Li, J. Pan, W. L. Qin, J. Yang and Y. L. He, Desalination, 2014, 351, 37-42.

20 B. Y. Gao and Q. Y. Yue, Chemosphere, 2005, 61(4), 579-584.

21 Z. L. Yang, B. Y. Gao, W. Y. Xu, B. C. Cao and Q. Y. Yue, J. Hazard. Mater., 2011, 189(1-2), 203-210. 
22 T. J. Chen, M. Niu, Z. Z. Wu and Y. Q. Xie, BioResources, 2015, 10(1), 1519-1527.

23 GB/T 17657, Standard Press of China, Beijing, China, 1999.

24 J. N. Brown and R. C. Brown, Bioresour. Technol., 2012, 103(1), 405-414.

25 A. Mujtaba, M. Ali and K. Kohli, Chem. Eng. Res. Des., 2014, 92(1), 156-165.

26 J. N. Sahu, J. Acharya and B. C. Meikap, Bioresour. Technol., 2010, 101(6), 1974-1982.

27 P. Singh, S. S. Shera, J. Banik and R. M. Banik, Bioresour. Technol., 2013, 137, 261-269.

28 W. Chen, W. P. Wang, H. S. Zhang and Q. Huang, Carbohydr. Polym., 2012, 87(1), 614-619.
29 M. Amini, H. Younesi, N. Bahramifar, A. A. Lorestani, F. Ghorbani, A. Daneshi and M. Sharifzadeh, J. Hazard. Mater., 2008, 154(1-3), 694-702.

30 T. J. Chen, M. Niu, Y. Q. Xie, Z. Z. Wu, X. Z. Liu, L. L. Cai and B. R. Zhuang, BioResources, 2015, 10(1), 538-547.

31 L. R. Tang, B. Huang, W. Ou, X. R. Chen and Y. D. Chen, Bioresour. Technol., 2011, 102(23), 10973-10977.

32 B. T. Tang, C. Wu, M. G. Qiu, X. W. Zhang and S. F. Zhang, Mater. Chem. Phys., 2014, 144, 162-167.

33 F. He, S. Chao, X. He and M. Li, Ceram. Int., 2014, 40(5), 6865-6874. 